\title{
Ofícios e estratégias de acumulação: o caso do despenseiro da Inquisição de Lisboa Antonio Gonçalves Prego (1650-1720)
}

\author{
Bruno Feitler* \\ Universidade Federal de São Paulo, São Paulo - SP, Brasil
}

\section{RESUMO}

Os palácios inquisitoriais, sedes dos tribunais do Santo Ofício, não eram apenas elementos arquitetônicos utilitários, mas assumiram uma relevância simbólica no seio da sociedade portuguesa do Antigo Regime. Isso ainda era mais forte em Lisboa, onde além de tribunal distrital, os Estaus também eram a sede do Conselho Geral e a residência do inquisidor geral. Neste artigo, pretendemos mostrar a importância do tribunal inquisitorial enquanto locus de afirmação social, a partir do exemplo de um daqueles que eram chamados de oficiais leigos da Inquisição (alcaide, meirinho, guardas etc.) e que, via de regra, assim como o inquisidor geral, residiam nos Estaus. No entanto, também mostraremos que essa importância ia mais além da simples certificação da pureza de sangue e que ela se entende apenas no âmbito de estratégias sociais mais amplas do indivíduo e de sua família.

Palavras-chave: Inquisição portuguesa; Estaus; mobilidade social; venalidade de ofícios.

\section{ABSTRACT}

Inquisitorial palaces, the court's headquarters, were not mere elements of useful architecture but had a symbolic relevance among Portuguese Ancien Régime's society. This is even more noticeable in Lisbon, where, besides being the district's tribunal, the Estaus (as it was called)were also headquarters to the Inquisition's Council General, and residence to the inquisitor

general. In this article, we intend to show the importance of the Inquisition as locus of social assertion through the example of one of the lay officials of the Inquisition (wardens, bailiffs, guards etc.). Usually, as the inquisitor general, they also dwelled in the Estaus.

Nevertheless,

we will also see that this importance surpassed the simple certification of purity of blood, and is only understandable within the person's and his family's broader social strategies.

Keywords: Portuguese Inquisition; Estaus; social mobility; venality of officials.

DOI - http://dx.doi.org/10.1590/2237-101X01703307

Artigo recebido em 22 de junho de 2015 e aprovado para publicação em 15 de novembro de 2015.

* Ecole des Hautes Etudes en Sciences Sociales; professor adjunto de História Moderna da Escola de

Filosofia, Letras e Ciências Humanas da Unifesp e professor colaborador do Programa de Pós-Graduação em

História da Universidade Federal da Bahia. Bolsista de produtividade nível 2 do CNPq. E-mail:

brunofeitler@gmail.com. Este artigo insere-se no projeto de pesquisa "Intergrupos: grupos intermédios em

Portugal e no império Português: as familiaturas do Santo Ofício (c. 1570-1773)"

(PTDC/HIS-HIS/118227/2010). Agradeço ao Senhor Luís A. Vasconcellos e Souza por gentilmente me facultar o acesso aos arquivos dos Viscondes de Vila Nova de Cerveira, à Luciana Gandelman e ao Tiago dos Reis Miranda por suas valiosas indicaçôes e comentários. 
Damiâo de Góis, em sua Descriçâa da cidade de Lisboa, identifica sete monumentos construídos pelos reis dignos de nota por "sua incrível magnificência e suntuosidade". "Na frontaria oposta [ao Hospital de Todos os Santos], passando um largo rossio a ocidente, levanta-se o terceiro monumento: edifício na verdade grandioso, digno de ser visto, pela sua arquitetura admirável, mandado erigir, à custa da naçấo, pelo infante d. Pedro, filho de d. João I. Mandou-o edificar quando regeu o reino em nome de d. Afonso V, seu sobrinho, com a intenção de que servisse para receber os embaixadores das naçóes e dos reis estrangeiros; também ali se hospedavam, por conta da nação, com todas as honras e grandezas". ${ }^{1}$ Pouco menos de vinte anos mais tarde o próprio Damiáo de Góis, sem honras ou grandezas, faria a experiência da hospedagem no suntuoso edifício enquanto réu da Inquisição. Interessante notar que em seu opúsculo sobre Lisboa de 1554, dedicado ao inquisidor geral d. Henrique, ele deixa de se referir às atividades inquisitoriais que já lá ocorriam. ${ }^{2}$ Com efeito, mesmo em 1538, ou seja, ainda antes da fundaçấo oficial do tribunal lisboeta no ano seguinte, os Estaus aparecem como "casa da samta Inquisiçam". ${ }^{3}$

$\mathrm{Na}$ verdade, a transformação de paço régio em sede do Santo Ofício português não foi imediata, mas tardou a se concretizar, as sessóes ocorrendo ora na capela de São Pedro-Mártir do convento de São Domingos, ora nos paços da Ribeira, ora nos Estaus, até que em 1584, segundo Julio de Castilho, ou em 1571, de acordo com Dejanirah Couto, o palácio do Rossio é definitivamente doado pela coroa à Inquisição. ${ }^{4}$ Ele é feito assim não só a sede do tribunal lisboeta, mas também da própria Inquisição portuguesa, transformando-se pouco a pouco, com a fixação da corte em Lisboa, no lugar de reunião dos deputados do Conselho Geral e na residência dos sucessivos inquisidores gerais.

A lenda negra da Inquisição portuguesa, ou seja, a produção historiográfica e literária liberal e anticlerical do século XIX, fixou a imagem dos Estaus sobretudo enquanto os cárceres do Santo Ofício; símbolo máximo do arbítrio, lugar tenebroso no qual as pessoas sofriam

${ }^{1}$ GÓIS, Damião de. Descriçâo da cidade de Lisboa. Lisboa: Frenesi, 2003 ([1554] trad. Raul Machado, 1. ed. 1937), p. 51 e 55-56. Os outros seis monumentos são a Misericórdia, o Hospital de Todos os Santos, o celeiro público, a Casa da Índia, o paço real e o arsenal.

${ }^{2}$ Damião de Góis foi processado por luteranismo em 1571. Ele abjurou seus erros in forma perante os inquisidores, o promotor fiscal e mais oficiais do Santo Ofício "nos Estaos, na casa do despacho em a mesa da Santa Inquisiçam" no dia 6 de dezembro de 1572. Cf. seu processo em Arquivos Nacionais da Torre do Tombo [ANTT], Inquisição de Lisboa [IL], processo 17170, fl. 157. Sobre as razóes do processo sofrido por Góis, ver o verbete a ele dedicado, escrito por José Pedro Paiva em PROSPERI, Adriano (Dir.). Dizionario Storico dell'Inquisizione. Pisa: Edizioni della Normale, 2010, v. II, p. 719-720.

${ }^{3}$ Ver ANTT, IL, processo 2725, fl. 1, contra Leonor Dias, de 1538. No título do documento consta no entanto que ela estava presa na cadeia da corte.

${ }^{4}$ Cf. CASTILHO, Julio de. Lisboa Antiga. Segunda parte, tomo IV, p. 221 da 1. ed., apud BAIÃO, António. A Inquisição em Portugal e no Brasil. Subsídios para a sua história. Lisboa: Arquivo Histórico Português, 1920, v. I, p. 11 e COUTO, Dejanirah. História de Lisboa. Algés: Gótica, 2004 [1. ed. em francês: 2000], p. 155. 
tormentos físicos e martírios psicológicos em celas estreitas e úmidas, por entre os ratos e a loucura. Imagem em grande parte verdadeira, mas também parcial. $\mathrm{O}$ paço dos Estaus encerrava, é claro, os cárceres secretos, os cárceres da custódia e os cárceres da penitência da Inquisição, sua casa do tormento e a mesa de despacho dos inquisidores, mas era também o palácio de residência do inquisidor geral, e dos dois ou três inquisidores que, ao assumir o cargo, para lá se mudavam, e assim também de toda uma série de serviçais, tanto desses senhores como da própria Inquisição: o alcaide dos cárceres, os carcereiros, o despenseiro, o meirinho com suas famílias. ${ }^{5}$ Deste modo, o próprio palácio não era apenas um elemento arquitetônico utilitário, mas assumiu uma relevância simbólica no seio da sociedade portuguesa e mais especificamente lisboeta de Antigo Regime. Neste artigo pretendemos mostrar a importância do tribunal inquisitorial enquanto locus de afirmaçáo social a partir do exemplo de um daqueles que podemos chamar de "oficiais menores" da Inquisição. Consideramos como oficiais menores aqueles que o regimento do Santo Ofício chama de "oficiais leigos" e que trabalhavam em continuidade nos tribunais. Seguindo a ordem em que são elencados no regimento de 1640, são eles o meirinho, alcaide, guardas, porteiro, solicitadores, despenseiro e homens do meirinho. ${ }^{6}$

A bibliografia mais recente sobre a burocracia de Antigo Regime chega a mencionar o fato de os ofícios menores da Inquisição, do mesmo modo que acontecia com ofícios da Coroa e de algumas grandes casas senhoriais e das ordens militares, terem sido patrimonializados e serem objeto de venalidade. ${ }^{7} \mathrm{O}$ único estudo específico sobre o tema, de autoria de Bruno Lopes, debruça-se de modo exploratório sobre o caso dos meirinhos do tribunal de Évora, descrevendo as diferentes modalidades de transmissão do cargo e os salários recebidos ao longo dos mais de cem anos em que o ofício esteve nas mãos dos descendentes de António

\footnotetext{
${ }^{5}$ Para uma história arquitetônica dos Estaus, ver: PINTO, Maria do Carmo Teixeira. Um palácio no Rossio: ciclos de vida (séculos XV a XIX). In: ACTA DAS SESSÓES. I COLÓQUIO TEMÁTICO: O MUNICÍPIO DE LISBOA E A DINÂMICA URBANA (SÉCUlOS XVI-XX). Lisboa: Câmara Municipal de Lisboa, 1995, p. 163-175.

${ }^{6} \mathrm{O}$ regimento individualiza por títulos próprios os seguintes ministros e oficiais com ordens: inquisidores, visitadores, deputados, promotor, notários, tesoureiro, procuradores dos presos [esse não necessariamente ordenado] qualificadores, comissários, visitador das naus de estrangeiros; e os seguintes oficiais laicos: meirinho, alcaide do cárcere secreto, guardas, porteiro, solicitadores, despenseiro, homens do meirinho, médico, cirurgião e barbeiro, familiares. Merece título separado o alcaide, guarda e capelão dos cárceres da penitência. Regimento do Santo Ofício de 1640, livro I, títs. 1 a 22. In: FRANCO, José Eduardo; ASSUNÇÃO, Paulo de. As metamorfoses de um polvo. Religião e política nos Regimentos da Inquisição portuguesa (séc. XVI-XIX). Lisboa: Prefácio, 2004.

${ }^{7}$ OLIVAL, Fernanda. Economía de la merced y venalidad en Portugal (siglos XVII e XVIII). In: ANDÚJAR Castillo, Francisco; FELICES de la Fuente, María del Mar (Ed.). El poder del dinero: ventas de cargos y honores en el Antiguo Régimen. Madri: Biblioteca Nueva, 2011, p. 345-357. Sobre os diferentes aspectos da venalidade em Portugal e no Brasil, ver: GALLO, Alberto. La venalidad de oficios públicos durante el siglo XVIII. In: BELLINGERI, Marco (Coord.). Dinámicas de Antiguo Régimen y orden constitucional. Representación, justicia y administración. Siglos XVIII-XIX. Turim: Otto Editore, 2000 e STUMPF, Roberta. Venalidad de oficios en la monarquía portuguesa: un balance preliminar. In: ANDÚJAR Castillo, Francisco; FELICES de la Fuente, María del Mar (Ed.). El poder del dinero, op. cit., p. 331-344.
} 
Pereira. Nessa análise, o cargo de meirinho aparece como central nas estratégias de ascensão de parentela da personagem. ${ }^{8}$ Se a apreciação de Lopes traz elementos importantes e é globalmente exata, a documentaçáo encontrada referente ao caso do despenseiro do tribunal de Lisboa parece indicar um lugar um pouco menos central (apesar de importante) do ofício inquisitorial nessas estratégias. O estudo que se segue tentará mostrar que, apesar de os cargos inquisitoriais terem uma importância pelo que toca às estratégias de afirmação social de um grupo familiar, essa relevância do ofício não passava pela sua função própria, mas apenas pelo seu vínculo institucional (imaginando que esse tipo de função também pode ser preenchido por outras instituiçóes, sobretudo tribunais). ${ }^{9}$ Ou seja, não me parece que tenham sido as funções de despenseiro do Santo Ofício que permitiram que nosso protagonista, Antonio Gonçalves Prego, ascendesse socialmente, mas sim uma série de funçóes que aparecem de maneira muito mais discreta na documentação inquisitorial mas que se revelam amplamente em outras fontes. Veremos assim um exemplo importante para se entender como o Santo Ofício - não tanto pelo mais óbvio instrumento da familiatura e a certificação de pureza de sangue dela decorrente, mas por todo um conjunto de ofícios do tribunal — servia às estratégias de afirmação social e de ascensão de uma camada intermédia da população urbana do Antigo Regime português. ${ }^{10}$

Em setembro de 1658, Antonio Gonçalves Prego entra com um pedido de habilitação no Santo Ofício de modo a poder tomar posse do cargo de despenseiro do tribunal de Lisboa. Agostinho Nunes, o proprietário do ofício de despenseiro (apesar de servir naquela época de alcaide dos cárceres), havia com efeito conseguido do Conselho Geral em setembro daquele ano autorização para renunciar ou vender este cargo em pessoa que fornecesse as verbas necessárias para que sua filha tomasse o estado de religiosa. Após as inquiriçóes de praxe, Prego foi considerado habilitado em 23 de novembro, e pouco tempo depois, no dia 27, o valor acordado entre Agostinho e ele, de 59\$000, foi depositado em dinheiro junto ao tesoureiro da Inquisição e só seria liberado diretamente para o mosteiro em que a moça fosse aceita. ${ }^{11}$

A venda ou renúncia do cargo era um dos modos de transmissão desses ofícios menores da Inquisição, mesmo se habitualmente a transmissão, com o aval do inquisidor geral, ou

\footnotetext{
${ }^{8}$ LOPES, Bruno. Família e Transmissão de cargos no Santo Ofício: o meirinho da Inquisição de Évora. In: SANTOS, Zulmira C. (Coord.). Família, espaço e património. Porto: CITCEM, 2011, p. 283-299. Disponíven em: <http://ler.letras.up.pt/uploads/ficheiros/10700.pdf>.

${ }^{9}$ Um caso que guarda certos paralelos, mesmo que num nível mais elevado, com o aqui estudado foi o dos Lopes de Lavre, cuja ascensão (mas não a fortuna) centrou-se no ofício de secretário do Conselho Ultramarino. Ver BICALHO, Maria Fernanda. Ascensão e queda dos Lopes de Lavre: secretário do Conselho Ultramarino. In: MONTEIRO, Rodrigo Bentes et al. Raizes do privilégio. Mobilidade social no mundo ibérico do Antigo Regime. Rio de Janeiro: Civilização Brasileira, 2011, p. 283-315.

${ }^{10}$ Sobre a familiatura, ver WADSWORTH, James. Familiari, Portogallo. In: PROSPERI, Adriano (Dir.), Dizionario Storico, op. cit., v. II, p. 577 e a bibliografia aí citada. Sobre a noção de grupos intermédios: DURÃES, Andréia. Grupos intermédios em Portugal (1600-1850). Uma aproximação ao vocabulário social. Topoi, n. 27, p. 318-343, dez. 2013.

${ }^{11}$ ANTT, Habilitaçôes do Santo Ofício [HSO], Antonio, maço 10, doc. 403, fl. 41.
} 
em sua ausência, do Conselho Geral, se fazia entre parentes, num sistema de remuneração de serviços que desembocava numa patrimonialização do cargo. Essa patrimonialização surge, no caso do ofício de despenseiro, desde o começo do século XVII: em primeiro de setembro de 1603 assume o cargo Pero da Silva, filho do defunto Francisco Manuel, que serviu muitos anos como despenseiro dos cárceres. ${ }^{12} \mathrm{O}$ fato de o cargo ser de propriedade aparece claramente alguns anos mais tarde, quando Domingos Heitor, então comprador ${ }^{13}$ da Inquisição, recebe a mercê do cargo de despenseiro como ajuda de casamento de sua filha Maria Lopes em 5 de dezembro de 1618. O cargo assim tem claramente uma função de reconhecimento e recompensa, já que Domingos Heitor nunca o ocuparia. O projeto de casamento ainda estava em embrião, pois João Nunes, que se casou com Maria, toma posse do cargo apenas em 29 de março de $1620 .{ }^{14}$ João Nunes é o despenseiro em título e efetivo da Inquisição de Lisboa até a sua morte, ocorrida em 1635. O cargo de despenseiro foi então ocupado por serventuários, até que em março de 1638 a viúva de João Nunes, Maria da Luz da Silva (seria uma segunda mulher do despenseiro, ou uma outra apelação de Maria Lopes?) recebe ordem do inquisidor geral "que se resolva casar com o dito ofício". ${ }^{15}$ A viúva recebera assim a herança do cargo, sempre como mercê do inquisidor geral, com uma propina de $16 \$ 000$ anuais, o resto do ordenado do despenseiro, que em 1644 perfazia $36 \$ 000$ réis, indo ao serventuário. ${ }^{16}$ Maria da Luz, no entanto, por "ser enferma e de poucas forças" e assim incapaz do serviço que a posição de mulher do despenseiro implicava, "que é [segundo a própria] imenso trabalho", se decide, ao receber o ultimato do inquisidor geral, a "ceder a dita mercê" ao seu cunhado, irmão inteiro do defunto João Nunes, de nome Agostinho Nunes, "à sombra" de quem Maria "ficaria com algum abrigo". Agostinho se criara na casa do irmão desde os quatro anos, e foi sem dúvida quem ficou servindo no cargo após a morte de João, e a personagem feminina a ajudar na intendência do cargo era a mãe de Maria, que vivia com eles. ${ }^{17}$

Interessante notar que na negociação entabulada entre Maria da Luz e o inquisidor geral sobre a transmissão do cargo de despenseiro, a viúva em busca de proteção não menciona a possibilidade da venda do cargo, mas apenas a vontade de viver resguardadamente à sombra do seu jovem cunhado. É verdade que a documentação sobre a venalidade dos ofícios é no mais das vezes elíptica, usando de um vocabulário que escamoteia as transaçóes financeiras

\footnotetext{
${ }^{12}$ ANTT, IL, livro 104, fl. 99v.

${ }^{13} \mathrm{O}$ cargo de comprador não é previsto em regimento e aparece apenas esta vez no registro das provisôes do tribunal de Lisboa. Trata-se provavelmente de um assistente do despenseiro. Segundo Bluteau é aquele "que todos os dias vai à ribeira ou à feira comprar o comer necessário para uma casa", como também podia ser considerado um tribunal como a Inquisição, para além das grandes casas nobres. BLUTEAU, Raphael. Vocabulario portuguez e latino (1712-1728). Disponível em: <http://www.brasiliana.usp.br/pt-br/dicionario/ edicao/1>.

${ }^{14}$ ANTT, IL, livro 104, fl. 212v.

${ }^{15}$ ANTT, HSO, Agostinho, maço 1, doc. 7, fl. 2.

${ }^{16}$ IL, livro 927, passim. O valor total do "mantimento e ordenado" de Agostinho Nunes e sua obrigaçáo de sustentar a viúva de seu irmão são mencionados em IL, livro 128, fl. 166v.

${ }^{17} \mathrm{HSO}$, Agostinho, maço 1, doc. 7, fl. 2.
} 
para deixar perpassar apenas a renúncia do cargo. ${ }^{18}$ Maria, muito pelo contrário, evoca a possibilidade de pagamento por parte dela para que o cargo fosse transmitido a seu cunhado: "e sendo necessário algum cabedal para entrar a servir, sua mãe dela suplicante lhe acudirá com dinheiro que da Índia lhe mandou seu marido pai dela suplicante."19

Vimos que cerca de 20 anos mais tarde o cargo seria transferido por uma soma de ao menos 59\$000. Apesar da patrimonialização evidente, seria ainda o cargo de despenseiro, naqueles anos finais da dominação filipina, isento de venalidade? Essa pergunta leva a algumas outras, que tentaremos responder ao mesmo tempo: quais os interesses de se possuir tal cargo? Que funçóes ele cobria? Responderemos a essas perguntas a partir de um personagem específico, aquele Antonio Gonçalves Prego nomeado despenseiro em 1658.

Antonio era natural de Lisboa, filho de um tirador de fios de ouro e neto de lavradores da região próxima de Lisboa. Sua família paterna era de Colares e a materna da freguesia de Santo Antão do Tojal. Sabe-se muito pouco sobre as rendas de Antonio e de sua família: seu pai, Luis Gonçalves, exercera seu ofício na rua dos Ourives do ouro e já era morto em 1658, e Antonio morava então com sua mãe, Ana Rodrigues, na rua das Esteiras, freguesia de São Nicolau de Lisboa. Sabemos também que os pais de Luis tinham um casal no pé da serra, termo de Sintra, que em 1708 ainda era de Antonio Gonçalves Prego e "prazo e foreiro aos bernardos da igreja de Santa Maria de Sintra em 3\$600 réis em dinheiro, e destes são $1 \$ 800$ em dinheiro pelo foro e outros $1 \$ 800$ pelo dízimo de todos os frutos, e assim não é obrigado a pagar dízimo". ${ }^{20}$ Teria sido assim a renda do casal, e quem sabe alguma herança paterna, que lhe permitiu adquirir o ofício inquisitorial que, é verdade, não representava em meados do século XVII uma soma muito importante.

Ao se habilitar, Antonio ainda estava solteiro, mas em janeiro de 1659 a habilitação de sua esposa, Felipa Nunes Correia, já havia sido feita e aprovada. Felipa era filha de um solicitador do Santo Ofício, José Nunes Pereira. José Nunes era por sua vez filho de familiar e genro do também familiar e ourives da prata Paulo das Neves. As testemunhas de sua habilitação, feita em 1640, eram todas ligadas aos ofícios da ourivesaria: douradores e guadamisileiros que confirmaram a filiação de José Nunes e de sua esposa. ${ }^{21} \mathrm{O}$ pai de Prego fora ourives, assim como também o fora seu irmão Domingos Gonçalves, igualmente descrito como engranzador de contas e também morador da rua dos Ourives do ouro antes de sua partida para a Índia, onde faleceu. ${ }^{22}$ Podemos assim pensar que a entrada de Antonio Gonçalves Prego (cujos pai e avós não eram habilitados pelo Santo Ofício) na lide inquisitorial se

\footnotetext{
${ }^{18}$ Ver OLIVAL, Fernanda. Economia de la merced, op. cit.

${ }^{19} \mathrm{HSO}$, Agostinho, maço 1, doc. 7, fl. 2.

${ }^{20}$ HSO, Antonio, maço 10, doc. 403, fl. 11 e Registo Geral de Testamentos, livro 155, fl. $192 \mathrm{v}$.

${ }^{21} \mathrm{HSO}$, José, maço 1, doc. 13, fl. 3-6v.

${ }^{22}$ HSO, Antonio, maço 22, doc. 643, fl. 9 e 16 e Segundo a habilitação na Ordem de Cristo de seu sobrinho Antonio Carvalho Prego, o pai e o irmão de Antonio Gonçalves Prego eram tiradores de prata, e não de ouro, além de engranzadores. ANTT, HOC, Antonio maço 48, n. 3, fl. 1.
} 
deu por essas relaçóes de ofício de seu pai e seu irmão e, mais ainda, pelo fato de sua esposa Felipa ser, além de neta de ourives, filha de oficial inquisitorial e neta de familiares da Inquisição. Antonio Gonçalves Prego, como mais tarde seu sobrinho Antonio Carvalho Prego, não seguiram a carreira de seus pais, deixando de lado os ofícios mecânicos para tentar a sorte em cargos de maior renda e prestígio: ofícios de finanças e a guerra, os cargos inquisitoriais ocupando um lugar específico em suas estratégias de afirmação social.

Mas o que podia representar ser despenseiro da Inquisição?

O cargo parece ter sido criado em 1571, quando o inquisidor-geral d. Henrique ordena que cada tribunal tenha efetivamente um despenseiro, de modo a que os mantimentos dos presos não tivessem mais que vir de fora "de mão de seus familiares, parente e amigos, donde nascia darem-se muitos avisos" ${ }^{23}$

O cargo era de alguma responsabilidade, e dava espaço para que seus ocupantes cometessem exações. O regimento da Inquisição de 1613 menciona a necessidade de se tomar contas ao despenseiro a cada seis meses, e ainda ordena aos inquisidores

que tenham muito cuidado de vigiar e ver se aos presos se dão os mantimentos bem acondicionados, e por sua justa valia, peso e medida; porquanto estas cousas há muitas faltas que os presos padecem: e achando que o despenseiro excede o modo, o repreenderão e admoestarão; e disso se fará termo assinado por ele. E fazendo o que não deve, darão disso conta ao inquisidor geral para prover no caso como parecer. $^{24}$

Com efeito, nos anos 1570 o despenseiro da Inquisição de Coimbra foi apanhado recebendo comissão da padeira dos cárceres (10 réis por cada tostão vendido), sendo provavelmente despedido em $1578 .{ }^{25}$

O regimento de 1640 , que retoma de certo modo o regimento específico redigido em 1571, deixa claro que a função do despenseiro era apenas a de prover aquilo que o alcaide dos cárceres lhe dissesse ser necessário para os presos, o despenseiro sendo terminantemente proibido de vender os produtos da despensa seja para "fora” seja para os ministros ou oficiais da Inquisição. Ele era o encarregado de pagar o barbeiro e a lavadeira todos os meses, de acordo com as contas do alcaide, e também comprar "tudo o que o tesoureiro lhe disser que é necessário para o Santo Ofício”. ${ }^{26} \mathrm{Ou}$ seja: tudo indica que o despenseiro dos cárceres cuidava apenas da intendência dos presos e não da dos ministros do Santo Ofício, que deviam

${ }^{23}$ Regimento do dispenseiro do Santo Ofício da Inquisição. ANTT, Inquisição de Coimbra, livro 271, fl. 43-44v publicado por MEA, Elvira. A Inquisição de Coimbra no século XVI. A Instituição, os homens e a sociedade. Porto: Fundação Eng. António de Almeida, 1997, p. 691-692.

${ }^{24}$ Regimento do Santo Ofício de 1613, $\$$ XXVII. In: FRANCO, José Eduardo; ASSUNÇÃO, Paulo de. As metamorfoses de um polvo, op. cit.

${ }^{25}$ MEA, Elvira. A Inquisição de Coimbra, op. cit., p. 152.

${ }^{26}$ Regimento do Santo Ofício de 1640, livro II, tít. XVIII. In: FRANCO, José Eduardo; ASSUNÇÃO, Paulo de. As metamorfoses de um polvo, op. cit. 
assim (inquisidor-geral, inquisidores residentes nos Estaus) gerenciar suas próprias casas. Segundo veremos logo adiante, o "necessário para o Santo Oficio" era provavelmente o que nos registros aparecem como miudezas. Nem por isso as somas gerenciadas pelo despenseiro seriam negligenciáveis, já que o tribunal de Lisboa, dependendo do período, teve uma relativamente grande população carcerária. Os livros de registro dos tesoureiros da Inquisição de Lisboa subsistem de modo aparentemente completo apenas a partir do ano de 1722, ou seja, seis anos após a morte de Antonio Gonçalves Prego, falecido em janeiro de $1716 .{ }^{27}$ Apesar de distar bastante no tempo do período de maior atividade do despenseiro, pensamos que os valores ali referenciados podem servir de base para avaliarmos os montantes que passavam pelas mãos do oficial. Vemos assim que em janeiro de 1722 haviam 48 homens e 18 mulheres presas. ${ }^{28}$ Referentes a esse mês, o despenseiro Pedro Álvares Vilaça, sucessor de Prego no cargo, recebeu do tesoureiro da Inquisição 256\$164 réis (fl. 8v), que contava pelo que era gasto de "ordinária” com cada preso (cujos valores variaram nesse ano entre 3\$398 e 3\$906 réis para cada homem por mês e $2 \$ 838$ e $3 \$ 286$ para cada mulher, com valores fixos por mês para todos), para além dos gastos com o barbeiro (40 réis por mês por preso), eventuais sangrias e visitas médicas, havendo também alguns gastos extraordinários não identificados dos próprios presos, como ainda um adicional de 400 réis recebido em dezembro por todos os presos. Só com essas despesas o despenseiro movimentava cerca de 3:400\$000 réis, aos quais vinham se adicionar gastos com “miudezas”, ou seja, azeite, vinagre, açafrão, ervas (como coentro e alecrim), mechas, papel, sal e sobretudo (pelos valores implicados) limpeza, aguadeiro, lavadeira e lenha, que contaram ao todo no ano por $160 \$ 000$ réis (fl. 81v). Para além disso o inquisidor João Pais do Amaral visitou os cárceres em 5 de março (fl. 63) e em 6 de agosto (fl. 67) daquele ano. Essas visitas, previstas em regimento, resultaram a cada vez na compra de vestuário para os presos: meias, sapatos, ceroulas, camisas, lençóis... num total de $174 \$ 500$ réis. Ou seja, em 1722 o despenseiro recebeu do tesoureiro do tribunal de Lisboa cerca de 3:735\$000 réis referentes a produtos usados para a alimentação e asseio dos presos do cárcere.

Os valores a serem gastos seja pelos presos ricos, seja pelos pobres eram decididos pelos inquisidores, que deviam ordenar ao tesoureiro do fisco que repassasse diretamente verbas para o tesoureiro dos tribunais (no caso dos presos pobres) ou que ordenasse aos depositários dos bens dos presos ricos que fornecessem as verbas necessárias ao mesmo tesoureiro, que as repassaria ao despenseiro. Uma vez tomadas as contas ao despenseiro pelos inquisidores (o

\footnotetext{
${ }^{27}$ Seu testamento foi aberto em 26 de janeiro de 1716. ANTT, Registo Geral de Testamentos [RGT], livro 155 , fl. $194 \mathrm{v}$.

${ }^{28} \mathrm{IL}$, livro 588, fl. 3-7. Os primeiros anos do século foram de movimento ligeiramente maior nos cárceres, com autos da fé nos quais foram reconciliadas mais de uma centena de pessoas por ano (1704, 1706, 1711, 1713), o número habitual variando entre algumas pessoas e seis dezenas por ano. Cf. MENDONÇA, José Lourenço D. de; MOREIRA, António Joaquim. História dos principais actos e procedimentos da Inquisição em Portugal. Lisboa: Círculo de Leitores, s.d. [1979].
} 
que deveria ser feito a cada seis meses), qualquer sobra de verba era devolvida ao tesoureiro ou juiz do fisco. ${ }^{29}$

Conseguiriam os despenseiros alguma porcentagem da parte dos fornecedores? Aumentariam eles os preços repassados nas contas dos presos, como temia o regimento de 1613 ? Podemos imaginar que algum tipo de margem havia, mas que, de modo a manterem-se discretos, ela não deveria ser de muita monta, sob pena nem que fosse da perda do cargo, como acontecera ao despenseiro de Coimbra. Se assim fizeram, devem ter sido extremamente cuidadosos, pois as pesquisas existentes não dão conta de nenhum processo aberto contra despenseiros do Santo Ofício, como pode ser o caso em relação a carcereiros e guardas. ${ }^{30}$

Supondo que Gonçalves Prego não tirasse benefícios dos montantes que circulavam pela despensa da Inquisição, de que rendas ele gozava? Antes de tudo, o despenseiro residia no palácio da Inquisição, o que sem dúvida minorava os gastos, além de fornecer um endereço dos mais respeitados. O regimento de 1640 diz que ele "assistirá de ordinário na despensa", o que contradiz o regimento dos despenseiros de 1571 que, ao descrever a despensa, diz explicitamente que "nesta casa da despensa não morará o despenseiro". ${ }^{11}$ Em todo caso, a documentação confirma que Antonio Gonçalves Prego morava nos Estaus. Em seu testamento ele menciona expressamente “[n]estas casas que são do ofício de despenseiro", e o termo de encerramento do testamento foi feito "por baixo do palácio da Inquisição e casas em que vive Antonio Gonçalves Prego". ${ }^{32}$ Não é possível saber exatamente onde ficavam as "casas" do despenseiro. Seria provavelmente um dos conjuntos de cômodos previstos para os "oficiais" do tribunal na planta traçada em 1632 pelo arquiteto Mateus do Couto. Como era habitual nos palacetes portugueses da época, esses cômodos tinham entrada independente do palácio da Inquisição, dando para uma ruela que da horta da mancebia se dirigia às portas de Santo Antão, como também o mostra o desenho dessa fachada, cujo primeiro andar era ocupado pelos cárceres da penitência. Há um outro pequeno conjunto de cômodos que dava para a fachada do nascente também previsto como sendo de uso dos oficiais. A mesma planta menciona um pequeno conjunto de três cômodos que, dando de um lado para o pátio central dos Estaus, são simplesmente chamados de "despensa". ${ }^{33}$ Do outro lado esse espaço comunicava por um vão (uma "ministra”) com o pátio dos cárceres, respeitando nisto o que diz o regimento de 1571, de modo que o despenseiro não tinha contato algum com os presos. ${ }^{34}$ Esse espaço de dois cômodos parece um tanto exíguo para albergar não só

\footnotetext{
${ }^{29}$ Regimento do dispenseiro do Santo Ofício da Inquisição. MEA, Elvira. A Inquisição de Coimbra, op. cit., p. 692.

${ }^{30}$ Cf. MARTINS, João Furtado. Corrupção e incúria no Santo Ofício. Ministros e oficiais sob suspeita e julgamento. Lisboa: Universidade Católica Portuguesa, 2015.

${ }^{31}$ Regimento do dispenseiro, op. cit., p. 691.

${ }^{32}$ RGT, livro 155, fl. 189v e $194 \mathrm{v}$.

${ }^{33}$ ANTT, CGSO, livro 140, fl. 3 a 8.

34 "Primeiramente se ordenará huma casa de despensas que sta junta ao carcer e tenha huma ministra, pella qual se de o mantimento ao alcaide e guardas e responderá esta ministra a outra casa ou varanda de dentro do carcer". Regimento do dispenseiro, op. cit., p. 691.
} 
o estoque de bens ligado ao cargo, mas também Antonio Gonçalves Prego e todos aqueles dados como residindo em sua casa, entre sobrinho e homens a seu serviço. ${ }^{35}$ Deste modo, o despenseiro devia ocupar dois espaços nos Estaus, a despensa e suas “casas”. Em todo caso, um endereço de prestígio.

De estipêndios anuais, os despenseiros recebiam 36\$000 réis, menos que os guardas dos cárceres, que recebiam $40 \$ 000$ (os estipêndios de um inquisidor nessa altura eram de $200 \$ 000$ réis). ${ }^{36} \mathrm{~A}$ essas cifras somavam-se várias parcelas adicionais. Quando eram realizados autos da fé (habitualmente não mais do que um por ano), ministros e oficiais recebiam propinas. Em 1644, o despenseiro recebeu $4 \$ 000$ réis (o mesmo que os guardas), enquanto os inquisidores receberam $20 \$ 000$ réis (fl. 34-35). Os oficiais da Inquisição (mas não os ministros), em 1644, também recebiam um adicional tendo em vista "serem os mais deles pobres e não lhes bastarem o ordenado para sua sustentação". O despenseiro recebia ainda $3 \$ 600$ réis (os guardas, $4 \$ 000)$. No natal os oficiais ainda recebiam dinheiro para comprar carne de porco, e na época da páscoa para comprar carneiro. O despenseiro, 700 a cada vez, e os guardas 450 (fl. 42-45). Ou seja: ao todo, em 1644, o despenseiro recebeu $45 \$ 000$ réis entre ordenado e propinas, um pouco menos que os guardas $(49 \$ 400)$ e cerca de um quinto do que recebiam os inquisidores (220\$000). Oitenta anos mais tarde, em 1722, esses valores não haviam mudado substantivamente. ${ }^{37} \mathrm{O}$ adicional por conta da carestia era sem dúvida maior (12\$000 para despenseiro e solicitadores, $8 \$ 000$ para os guardas, e também $40 \$ 000$ para os inquisidores, que não o recebiam em 1644), e ministros e oficiais recebiam suas partes da tença do rendimento do tabaco (40\$000 para inquisidores, $10 \$ 000$ para o despenseiro, $6 \$ 000$ para os guardas) ${ }^{38}$, mas o salário-base continuava o mesmo para o despenseiro e inquisidores, enquanto os guardas tiveram um aumento substancial: de 40 passavam a receber $90 \$ 000$ réis anuais. Na verdade esse aumento do total das rendas foi um pouco menor, já que em 1722 não houve auto da fé, o que teria elevado um pouco mais a diferença. Interessantíssimo o quanto variou a renda dos guardas dos cárceres: um meio de diminuir as possibilidades de corrupção desses oficiais em

\footnotetext{
${ }^{35}$ No processo de habilitação de Pedro Álvares Vilaça, datado de 1696, tanto ele quanto as testemunhas Salvador Pereira e Antonio Cardoso Prego afirmam viver na casa de Antonio Gonçalves Prego, apesar de já terem naquele momento seus próprios ofícios inquisitoriais - tendo assim direito a seus aposentos ou verbas extras de aposentadoria. Salvador Pereira tinha o ofício de solicitador da Inquisição e o sobrinho de Gonçalves Prego, o de porteiro do tribunal. HSO, Pedro, maço 10, doc. 254, inquirição de 5 de setembro de 1696. Sobre a simplicidade da maioria das moradas em Portugal, ver OLIVAL, Fernanda. Os lugares e espaços do privado nos grupos populares e intermédios. In: MATTOSO, José. História da vida privada em Portugal. A Idade Moderna (Coord. De N. G. Monteiro). Lisboa: Círculo de Leitores/ Temas e Debates, 2010, p. 244-263.

${ }^{36} \mathrm{IL}$, livro 927.

${ }^{37} \mathrm{IL}$, livro 634.

${ }^{38}$ Essa tença adicionou-se às rendas da Inquisição por provisão régia datada de 1718. Cf. FIGUEIRÔA-RÊGO, João. Entre honra e suspeita. A desconcertante ambiguidade social dos agentes do tabaco nos séculos XVII e XVIII. In: LÓPEZ-SALAZAR, Ana Isabel; OLIVAL, Fernanda; FIGUEIRÔA-RÊGO, João (Coord.). Honra e sociedade no mundo ibérico e ultramarino. Inquisição e ordens militares. Séculos XVI-XIX. Casal de Cambra: Caleidoscópio, 2013, p. 274-275.
} 
Bruno Feitler

contato cotidiano com os presos? Uma busca por processos contra carcereiros poderia eventualmente responder a essa pergunta. Fiquemos por ora com o nosso despenseiro.

Total de ordenado e propinas (1644 e 1722)

\begin{tabular}{|c|c|c|c|}
\hline & Inquisidores & Despenseiro & Guardas \\
\hline 1644 & $220 \$ 000$ & $45 \$ 000$ & $49 \$ 400$ \\
\hline 1722 & $280 \$ 000$ & $59 \$ 400$ & $104 \$ 860$ \\
\hline$\%$ aumento & $27,3 \%$ & $32 \%$ & $112,3 \%$ \\
\hline
\end{tabular}

Ou seja, tendo em vista apenas o que recebia, em dois ou três anos de atividade, e com o cinto apertado, o despenseiro reembolsava-se do investimento para a compra do cargo (59\$000 réis em 1658), com alguma folga.

Além das questões de sobrevivência e de retorno financeiro, não podemos deixar de descrever os privilégios atinentes ao cargo de oficial inquisitorial. Esses dados são já bem conhecidos, mas eles devem ser rapidamente revistos aqui. $\mathrm{O}$ cardeal $\mathrm{d}$. Henrique, enquanto inquisidor-geral, obteve de seu sobrinho-neto d. Sebastião vários privilégios para os ministros, oficiais e familiares inquisitoriais, promulgado ele próprio enquanto monarca alguns outros, sobretudo o privilégio de foro. ${ }^{39}$ Privilégios suntuários, financeiros e legais que foram confirmados pelos Felipes mas também restringidos a partir dos anos 1680 pelo que toca os familiares da Inquisição, aqueles oficiais leigos sem funçóes cotidianas. Essas restrições, no entanto, não afetaram os ministros nem tampouco os oficiais leigos dos tribunais do Santo Ofício, que continuaram gozando das isenções fiscais e do privilégio de foro. ${ }^{40}$ Veremos mais à frente qual pode ter sido o impacto desses privilégios na carreira do despenseiro, mas para isso é importante ver primeiro que suas preocupaçóes, iam muito além do Rossio.

O testamento de Gonçalves Prego, redigido em 6 de março de 1708, ou seja, depois de exatos 50 anos de serviço no cargo de despenseiro do Santo Ofício, mostra que o oficial exercia outras duas atividades: além de emprestar dinheiro a juros, também era o prioste do cabido da Sé de Lisboa, gerenciando assim as rendas de uma das catedrais mais ricas do reino. Seu testamento também mostra que além da propriedade familiar de Sintra, Prego também tinha, no momento da redação do seu testamento, outras terras, cuja administração sem dúvida ocupava parte do seu tempo. ${ }^{41}$

${ }^{39}$ Cf. Traslado autentico de todos os privilegios concedidos pelos Reys destes Reynos, e Senhorios de Portugal aos Officiaes, e Familiares do Santo Officio da Inquisição. Lisboa: Na Officina de Miguel Manescal, 1691.

${ }^{40}$ Sobre os privilégios e suas restrições, ver WADSWORTH, James. Os familiares do número e o problema dos privilégios. In: VAINFAS, Ronaldo; LAGE, Lana; FEITLER, Bruno (Org.). A Inquisição em xeque: temas, controvérsias, estudos de caso. Rio de Janeiro: EdUERJ, 2006, p. 97-111.

${ }^{41}$ RGT, livro 155, fl. 183-194. Os testamentos e suas riquíssimas informaçôes dão espaço para uma vasta gama de análises que deixaremos de lado aqui para nos concentrarmos nas informaçóes que possam ser mais importantes para a compreensão do ofício de despenseiro na vida do testador. A bibliografia sobre o tema é vastíssima. Ver inter alii a bela análise de Luciana Gandelman e a bibliografia aí citada. GANDELMAN, 
Ofícios E ESTRATÉGIAS DE ACUMULAÇÃO: O CASO DO DESPENSEIRO DA INQUiSiÇÃO DE LisboA Antonio Gonçalves Prego (i 650 - I720)

Bruno Feitler

Impossível saber exatamente qual seria o montante de dinheiro implicado nos seus empréstimos, já que o testamento menciona apenas que um de seus fiéis servidores, que apresentaremos mais adiante, estava a par dos débitos:

Declaro que se me está devendo muito dinheiro e muito dele se me está devendo a razão de juro por escrituras e prescritos dos devedores, e que destes, muitos têm penhores nesta casa, de prata, ouro e joias e armaçôes de panos de rás em cauçôes de suas dívidas, e destes devedores me fez um livro Salvador Pereira. ${ }^{42}$

Importante notar que essa atividade de prestamista não coloca necessariamente Antonio Gonçalves Prego no cume econômico da sociedade lisboeta. Com efeito, ainda na segunda metade do século XVIII boa parte das atividades creditícias era efetuada por uma grande quantidade e tipologia de pessoas e não estavam restritas a um grupo específico (como podia ser o caso na mesma época em outros grandes centros europeus). Havia assim uma "dispersão do sistema de crédito" e uma "difusão social dos credores", com um papel importante dos membros dos grupos intermédios da populaçáo, onde podemos encaixar Antonio Gonçalves Prego. ${ }^{43}$

Será quem sabe possível resgatar por meio dos registros notariais os nomes de alguns dos seus devedores e os montantes implicados, mas uma primeira tentativa mostrou-se infrutífera. Podemos no entanto ter uma ideia da fortuna do despenseiro ao somar o que, sem dúvida com algum otimismo - ele pensava poder despender para o bem de sua alma, de sua memória entre gastos com seu funeral, missas, rendas para seus próximos e doaçôes a instituiçóes diversas e variadas. Apenas em legados e esmolas diretas a instituiçóes e pessoas a serem feitos em dinheiro, previa-se um gasto de mais de 4:300\$000 réis, sem contar as dotaçôes em rendas anuais para toda a vida a parentes e servidores de um montante total de $400 \$ 000$ em padrốes de juros a serem entregues à Misericórdia de Lisboa para sua repar-

Luciana. O poder dos bens deste mundo: um exercício de indagação sobre o testamento seiscentista de João de Matos de Aguiar. In: SÁ, Isabel dos Guimarães; GARCÍA FERNÁNDEZ, Máximo (Org.). Portas adentro: comer, vestir, habitar (ss. XVI-XIX). Coimbra/Valadollid: Imprensa da Universidade/Secretariado de Publicaciones, 2010, p. 273-293. Disponível em: <https://digitalis.uc.pt/pt-pt/livro/o_poder_dos_bens_deste_mundo_um_exerc\%C3\%ADcio_de_indaga\%C3\%A7\%C3\%A3o_sobre_o_testamento_seiscentista_ de_jo\%C3\%A3o>.

${ }^{42}$ E continua: "porém, não estando no dito livro todos os devedores, nem todos os escritos, nem escrituras, e na caixa que está na minha câmara que abre a tampa por cima, estão muitos maços de escrituras e escritos destes devedores, e como Salvador Pereira melhor sabe destes devedores, a ele peço que dando tudo conta e as clarezas que lhe for possível achar aos Senhores meus testadores, ajuste por sua ordem com cada um dos ditos devedores o que devem de $\mathrm{p}^{\text {ol }}$ [?] e réditos para se poder cobrar e assim se der cumprimento a este testamento". RGT, livro 155, fl. 192-192v.

${ }^{43}$ Sobre o sistema de crédito na Lisboa da época moderna, ver ROCHA, Maria Manuela. Crédito privado em perspectiva comparada (séculos XVII-XIX). Gabinete de História Económica e Social: Lisboa, 1998. Disponível em: <http://www.repository.utl.pt/bitstream/10400.5/908/1/WP10.pdf>. 
tição. Caso ele próprio não tivesse comprado esses padróes antes de sua morte, Gonçalves Prego previa que a venda da prata e dos móveis não dispostos em testamento, assim como o dinheiro procedido da execução de suas dívidas, seriam suficientes para cobrir esse valor. ${ }^{44}$ Ele ainda determina o pagamento de salário de seus servidores durante o (longo) tempo que previa para a execução do testamento. Em bens imóveis Antonio menciona em seu testamento várias propriedades cujos prazos passariam a seu sobrinho e provável afilhado Antonio Carvalho Prego: a quinta de Carenque, termo de Lisboa, junto com a fazenda e três hortinhas que a ela foram incorporadas, foreira às freiras do Salvador; a quinta dos Castanhais, por baixo de Sintra, foreira à igreja de $S$. Martinho de Sintra; o casal do Trapouce, também termo de Sintra e foreiro ao Hospital Real de Todos os Santos; o casal já mencionado que havia sido de seus avós, também no termo de Sintra. Mas sua propriedade de predileção era sem dúvida a quinta do chafariz de Andaluz, em Lisboa, na qual mandou construir a ermida de Nossa Senhora do Cabo, de sua especial devoção. ${ }^{45} \mathrm{Ou}$ seja, em todo caso um patrimônio que nem de longe condiz com as rendas de um despenseiro da Inquisição, e que fazia parte de estratégias cujos resultados foram certeiros: a Senhora do Cabo era "celebrada com muita solenidade todos os anos em o mês de agosto", sem dúvida com a menção do nome do seu instituidor, e Francisco Antonio Prego, provavelmente sobrinho-bisneto de Antonio Gonçalves, era dado como o titular de um morgadio e morador, em 1758, "em uma barraca" na quinta do chafariz do Andaluz. ${ }^{46}$

A principal atividade exercida por Antonio Gonçalves Prego não podia assim ser a de despenseiro. Vimos que ele emprestava dinheiro, inclusive por acordos notariais e por vezes implicando penhora, mas sua função de prioste do cabido de Lisboa sem dúvida devia lhe render bons dividendos, além de indicar ótimas relações sociais. Nos arquivos da cúria patriarcal de Lisboa foi possível encontrar indícios dessa atividade. A documentação não é relativa às rendas do cabido, mas sim da mitra. Em 1687, o arrendamento da massa grande do arcebispado de Lisboa (a "mitra do Ilustríssimo Senhor Luis de Souza, arcebispo de Lisboa”) perfazia um valor de 13:500\$000 réis, divididos entre três rendeiros, sendo um deles Simão Diniz, de quem Antonio Gonçalves Prego era fiador de um valor de 3:600\$000 reis (ou 9 mil cruzados). Esse valor era pago por Gonçalves Prego aos quartéis em dinheiro,

\footnotetext{
${ }^{44}$ RGT, livro 155, fl. 187-188. Sobre o papel das Misericórdias no gerenciamento desses legados, ver AMORIM, Inês. Património e crédito: Misericórdia e Carmelitas de Aveiro (séculos XVII e XVIII). Análise Social, n. XLI, p. 693-729, 2006.

${ }^{45}$ RGT, livro 155, fl. 190v e 192v. Muito provavelmente é essa quinta a que se referem PORTUGAL, Fernando; MATOS, Alfredo de em sua Lisboa em 1758. Memórias paroquiais de Lisboa. Lisboa: Publicaçóes Culturais da Cámara de Lisboa, 1974. No capítulo dedicado à paróquia de Sáo Sebastiáo da Pedreira consta um chafariz do Andaluz (p. 249) e também uma ermida de Nossa Senhora do Cabo, à rua direita "vulgarmente chamada a ermida do Prego" (p. 259).

${ }^{46}$ Ibidem, p. 259. Antonio Carvalho Prego, sobrinho do despenseiro, faleceu em janeiro de 1719 e nomeia em seu testamento apenas um filho, chamado Antonio Gonçalves Prego. RGT, livro 156, Al. 46-51. A barraca é sem dúvida uma consequência das destruições causadas pelo terremoto de 1755 .
} 
em cevada e até em dívidas referentes à pensão que a Inquisição tinha nas rendas da mitra. No ano seguinte ele próprio já aparece como rendeiro, e em 1690 fez-se-lhe novo contrato de arrendamento das rendas da massa grande do arcebispado ainda no mesmo valor, e mais uma vez em $1694 .{ }^{47}$ No mesmo período ele também aparece como o rendeiro de parte da massa pequena das rendas, de um valor que variou entre 14 mil e 15 mil e 500 cruzados por ano, entre 1689 e $1694 .^{48}$

Em 1700, Prego é dado como prebendeiro ou prioste do cabido de Lisboa (e não mais da mitra), fazendo pagamentos referentes a processos corridos no juízo episcopal. Ele aparece assim como depositário de frutos que haviam sido sequestrados da conesia de Mafra por conta de um litígio com o visconde de Vila Nova de Cerveira. Um recibo de $700 \$ 000$ réis foi passado em 28 de novembro de 1700, outro de um conto de réis em 6 de outubro de 1702 e ainda um de 500\$000 réis referente a meio ano, datado de 10 de junho de $1703 .{ }^{49}$

O quanto Antonio Gonçalves Prego tirava dessas transações vultuosas, o quanto rendia o gerenciamento, primeiro das rendas da mitra do arcebispado de Lisboa e em seguida do cabido da Sé, é difícil de dizer. Em todo caso, sem dúvida bem mais do que os cerca de $60 \$ 000$ réis que tirava por ano do seu cargo de despenseiro da Inquisição. Os vínculos com a Sé de Lisboa, seja com a casa do arcebispo d. Luis de Souza (1675-1702), seja com o cabido, eram mais importantes financeiramente para Antonio Gonçalves Prego, e assim também para o aumento da sua casa, do que aquele que o unia ao tribunal do Santo Ofício. Um passo do seu testamento aponta para uma hierarquia que mescla elementos que se vinculam a deveres sociais do despenseiro enquanto cliente a dados que se ligam ao foro da intimidade. Ao instituir quatro capelas de missas cotidianas "para sempre” na Sé de Lisboa, os quatro capelães deveriam ser selecionados, por meio de oposição, pelo cabido da Sé, que também administraria as capelas, "pelo muito que desejei sempre servir ao reverendo cabido e por serem os capelães delas para servirem na dita Sé”; demonstração clara da subserviência do testador ao cabido. ${ }^{50}$

Prego tem o cuidado de detalhar quais as tarefas dos capeláes: rezar por ano 300 missas (as outras 65 ficando livres), rezando no coro as horas canônicas. No caso de impedimento, deverão eles mesmos providenciar um substituto. Ele também descreve as qualidades dos capelães - saber cantochão, ser de boa vida e costumes "de sorte que também por esta causa Deus se agrade de seus sacrifícios" - mas também uma preferência por candidatos que fossem filhos ou netos de oficiais do Santo Ofício. A Inquisição assim surge numa posição mais orgânica, sem a necessidade de se explicitar a razão dos vínculos. Isso aparece mais uma

\footnotetext{
${ }^{47}$ Arquivo da Cúria Patriarcal de Lisboa, Livro 468 - Rendas da mitra, fls. 2-12v.

48 Arquivo da Cúria Patriarcal de Lisboa, Livro 468 - Rendas da mitra, fls. 20-28v.

${ }^{49}$ Viscondes de Vila Nova de Cerveira [VVNC], cx. 44, n. 4, 5 e 6.

${ }^{50}$ Sobre o "delírio ritual no teatro do culto" que a passagem de um mundo ao outro implicava no Portugal do século XVIII, ver ARAÚJO, Ana Cristina. A morte em Lisboa. Atitudes e representaçóes. 1700-1830. Lisboa: Notícias Editorial, 1997, p. 242 sq.
} 
vez na hierarquia em que apresenta em nome de quem essas missas deveriam ser rezadas. $\mathrm{O}$ primeiro capelão rezaria pelo arcebispo d. Luis de Souza: "pelas grandes honras que do dito Eminentíssimo Senhor Cardeal recebi.” O segundo capelão deveria dizer missas pelas almas dos "cônegos capitulares desta Sé que o foram desde que fui prebendeiro do reverendo cabido até o tempo da minha morte e pela saúde e vida dos que de presente são vivos e pelas almas depois de mortos". Mesmo depois de mortos d. Luis e os cônegos continuariam a receber as honras que Antonio Gonçalves Prego lhes rendia sem dúvida em vida. $\mathrm{O}$ terceiro capeláo rezaria pelas almas da defunta esposa de Prego, Felipa Nunes, e por aquela de sua também defunta filha, soror Josefa do Espírito Santo. O último capeláo celebraria missas pelas almas de seus pais, avós e demais parentes, mas também "pela exaltação do tribunal do Santo Ofício". A Inquisição vem nomeada em último lugar, e de modo vago. Prego não teria assim nenhum vínculo com inquisidores ou deputados em especial que valessem uma menção em seu testamento, apesar de ser sem dúvida da confiança de alguns (o inquisidor João Duarte Ribeiro era um dos seus testamenteiros) e ter negócios com outros, que também eram membros do cabido de Lisboa: o deputado da Inquisição Felipe Barbosa tivera contas com ele "sobre uns moios de trigo que [lhe] deu"; ${ }^{51}$ com o também deputado e deão da Sé de Lisboa José de Vasconcelos e Souza "tinha contas largas [...] e cobrava várias rendas minhas [do deão] até este presente ano" além de ter empenhado com ele um candeeiro de prata"; 52 e ainda o inquisidor Roque Ribeiro de Abreu lhe devia três moios de cevada, e Prego $48 \$ 000$ réis a ele. ${ }^{53}$

Apesar de não surgirem nos seus velhos dias nenhuma menção de subserviência a membros específicos do alto escalão do tribunal inquisitorial, como aparece em relação à Sé, a ligação com o Santo Ofício era mais antiga e, como já dissemos, também mais orgânica e mais íntima. Era o Santo Ofício que estruturava o seu cotidiano, não só por ele morar no palácio do tribunal, mas por lhe servir de base para a sua casa.

Alguns anos depois de assumir o ofício de despenseiro ele chegou a pensar em abandonar o cargo de modo a dotar a sua filha, obtendo em 1668 autorização para isso. E nesse mesmo ano ele ocupou provisoriamente a serventia do ofício de solicitador da Inquisição. ${ }^{54}$ Sua única filha viva, Josefa do Espírito Santo, entrou no entanto no convento da Anunciada sem fazer uso do ofício, e Antonio impetrou então outro pedido de renúncia dele, em 1677, desta vez para dote de sua irmá Maria do Espírito Santo. Outra vez Antonio prefere manter o cargo, dotando sua irmã de outro modo, pois em 1679 ele já lhe tinha dado estado, casando-a com o capitão Jerônimo Nobre Morato. Ou seja, desde essa época suas atividades lhe permitiam acumular bens suficientes para dotar confortavelmente a sua família sem a necessidade de alienação do ofício de despenseiro. Em 1679 ele obtém outra autorização de renúncia do cargo, desta vez para seu sobrinho órfão Antonio Carvalho Prego, mas uma

\footnotetext{
${ }^{51}$ RGT, livro 103, fl. 10-11v. Testamento de Felipe Barbosa, de 8 de fevereiro de 1704.

${ }^{52}$ RGT, livro 106, fl. 89v. Testamento de João de Vasconcelos e Souza, de 3 de fevereiro de 1705.

${ }^{53}$ RGT, livro 107, fl. 119. Testamento de Roque Ribeiro de Abreu de...

${ }^{54} \mathrm{IL}$, livro 106, fl. 177v. Provisão em 17 de fevereiro de 1668.
} 
renúncia que se tornaria efetiva apenas depois de sua morte. ${ }^{55}$ Em 1694 o sobrinho Carvalho Prego, já então cavaleiro da ordem de Cristo (obtido por renúncia dos serviços de um tio que de soldado chegou a capitão de infantaria durante a guerra de Restauração), ${ }^{56}$ aparece comprando um ofício de porteiro da casa de despacho da Inquisição. ${ }^{57}$ A fortuna de Gonçalves Prego não parou de aumentar: em 1698 ele emprestou 5 mil cruzados (ou seja, 2 contos de réis) para que este mesmo sobrinho comprasse o ofício de escrivão do Fisco real (ofício também ligado à Inquisição, mas, como se vê, muito mais caro e sem dúvida mais rentável que os ofícios do próprio tribunal), verba à qual o tio renuncia graciosamente em $1710 .{ }^{58}$

Os postos inquisitoriais não serviam apenas como elemento de estruturação social de seus parentes, mas também de outros membros de sua casa, como seus fiéis servidores. Ao entrar no ofício de escrivão do Fisco, Carvalho Prego passa, em dezembro de 1698, a serventia do cargo de porteiro da Inquisição ao servidor do seu tio de nome Salvador Pereira, ${ }^{59}$ que nesse momento já era proprietário do um dos ofícios de solicitador, comprado por Gonçalves Prego por 600\$000 réis em 1694 (Salvador Pereira, desde então e até a morte de seu patrão, deixou de receber o salário anual de $60 \$ 000$ réis para reembolso da verba gasta). ${ }^{60}$ Pereira, filho de sapateiro, ${ }^{61}$ era um dos homens de confiança de Gonçalves Prego, a seu serviço desde 1688. Segundo o testamento do despenseiro, ele "tem grande préstimo, verdade e inteligência, e sabe todos os particulares desta casa, e sem ele e suas notícias se não poderão dispor as cobranças e fazer os ajustamentos das contas com o grande número de pessoas que a esta casa são devedores".

Antonio Gonçalves Prego ainda dotou um outro membro de sua casa com um ofício inquisitorial. Depois de prever sucessivamente a transferência de seu posto de despenseiro para sua sobrinha, para sua irmã e para seu sobrinho, finalmente, em 5 de abril de 1710, obtém do inquisidor geral a autorização para deixar, depois de sua morte, o cargo a seu caixeiro Pedro Álvares Vilaça, que, como Salvador Pereira, vivia na casa de Gonçalves Prego. ${ }^{62}$ Pedro Álvares Vilaça servia a Prego havia mais de trinta anos e tinha, sobre os particulares da casa de Prego, "tanta notícia como eu”. Em testamento, Gonçalves Prego deixou tanto a Salvador

\footnotetext{
55 Todas essas informaçóes aparecem na habilitação de familiar do sobrinho. HSO, Antonio, maço 22, doc. 643, fls. $1-2 \mathrm{v}$.

${ }^{56} \mathrm{Na}$ verdade foi sua prima Josefa Sobrinha quem renunciou da renda e do hábito. Carvalho Prego havia também servido enquanto soldado, "fazendo sua obrigação assim em sentinelas, rondas e fainas marítimas" na capitânia Real São Francisco de Assis, em 1682. HOC, Antonio, maço 48, n. 3, fl. 3. Carvalho Prego obtém a dispensa de seus defeitos mecânicos em 28 de junho de 1686 (fl. 5).

${ }^{57}$ IL, livro 107, fl. 478v. Provisão de 29 de março de 1694.

${ }^{58}$ ANTT, Registros notariais de Lisboa [RNL], cartório 15A [antigo 7A], cx. 86, livro 471, fl. 62v.

${ }^{59}$ IL, livro 108 , fl. $168 \mathrm{v}$.

${ }^{60} \mathrm{IL}$, livro 108, fl. 2. RGT livro 155, fl. 188v.

${ }^{61} \mathrm{HSO}$, Salvador, maço 1, doc. 15.

${ }^{62}$ A renúncia foi registrada em cartório de modo a evitar problemas com o sobrinho, em quem havia anteriormente feito a renúncia: RNL, cartório 15A [antigo 7A], cx. 86, livro 471, fl. 63. É-lhe dado o título de caixeiro pelo próprio Antonio Carvalho Prego no processo de habilitação. HSO, Pedro, maço 10, doc. 254.
} 
quanto a Pedro $600 \$ 000$ réis para compra de um ofício, o que não foi alterado depois da promessa de renúncia do cargo de despenseiro. É evidente que tanto Salvador Pereira quanto Pedro Álvares Vilaça ocupavam funçôes estratégicas nas atividades de Antonio Gonçalves Prego, ajudando-o no gerenciamento de suas rendas e naquelas do cabido de Lisboa. Isto fica claro no texto do testamento de Gonçalves Prego e aparece também em documentação anexa. É por exemplo Pedro Álvares Vilaça quem recebe "nesta casa do Sr. Antonio Gonçalves Prego" vários carregamentos de trigo entre 1703 e 1705 das rendas do visconde de Vila Nova de Cerveira referentes à conesia de Mafra, assinando ele próprio os recibos. ${ }^{63} \mathrm{O}$ quadro náo ficará completo se não elencarmos aqui o conjunto de membros da casa do despenseiro. Segundo seu testamento, Antonio Gonçalves Prego tinha ainda a seu serviço um terceiro caixeiro, em sua casa a menos tempo que Pereira e Vilaça, chamado Francisco Pinto Ferraz (e que também acabaria, mais tarde, por ter um ofício inquisitorial); ${ }^{64}$ um certo Félix Vieira Dantas, a seu serviço havia 25 anos, durante os quais foi aprovado como cirurgião, permanecendo mesmo assim em sua casa; dois servidores "de escada abaixo", um chamado Manuel e o outro José Prego, escravo alforriado por Antonio Gonçalves e que lá permaneceu como seu criado. ${ }^{65}$

Ao fim de sua vida, Antonio Gonçalves Prego havia assim acumulado em sua casa, seja pessoalmente, seja por meio de seu sobrinho e criados, os ofícios de despenseiro, porteiro e solicitador do tribunal de Lisboa, além daquele de escrivão do fisco. Ofícios que eram para seus proprietários fonte de rendimentos não muito altos, mas certos. Sobretudo, o que transpira desse acúmulo é a impressão de que para ele os ofícios serviam de meio de retribuição afetiva e de serviços, como se ele se apropriasse, dentro da lógica da economia da mercê, de alguns ofícios inquisitoriais de modo a melhor estabelecer na sociedade tanto o seu sobrinho e sucessor quanto seus serviçais de muitos anos.

Antes de concluir, não podemos desprezar as vantagens mais efetivas que um cargo na Inquisição outorgava para além do certificado de pureza de sangue. Com efeito, os privilégios financeiros e jurídicos atinentes ao ofício também podiam ser grandes atrativos para alguém que como Prego lidava com negócios de crédito.

Ao menos por duas vezes Antonio Gonçalves Prego pode invocar em juízo seu privilégio inquisitorial de foro, em ambas as vezes como réu, uma em 1679 e outra em 1683. No primeiro processo ele aparece como fiador de um certo João da Silva, que devia $14 \$ 000$ réis ao autor do processo. Os inquisidores que julgaram o caso deram razão a Prego, que afirmou que primeiro deveria ser executado o devedor principal. O segundo processo, que parece estar mais relacionado com sua atividade de despenseiro do Santo Ofício (o pagamento ao carpinteiro do Santo Ofício referente a madeira para fazer carvão), implicava somas maiores:

\footnotetext{
${ }^{63}$ VVNC, cx. 59, n. 53 e 54.

${ }^{64}$ Francisco Pinto Ferraz sucederá a Salvador Pereira no ofício de porteiro da mesa do despacho em maio de 1730. IL, livro 112, fl. 5.

${ }^{65}$ RGT, livro 155, fl. 189-194v.
} 
uma margem ("preferência”) de $80 \$ 000$ réis segundo o carpinteiro, ou de $63 \$ 000$, segundo Prego, que também ganhou a causa, confirmada inclusive em apelo pelo Conselho Geral. ${ }^{66}$ Em todo caso, não eram somas gigantescas. Gonçalves Prego parece assim ter tirado poucas vantagens nos julgamentos, apesar de ter ganhado ambos. Orientamos atualmente um estudo sobre a questão da importância desse privilégio de foro no âmbito do Santo Ofício. Seriam os oficiais inquisitoriais julgados nesses processos com mais leniência? Em todo caso tratava-se um modo de demarcar ainda mais o vínculo do oficial como membro do corpo inquisitorial e que ele não poderia, sem afrontar o próprio tribunal, ignorar.

Os privilégios fiscais podiam oferecer vantagens mais palpáveis. Uma carta régia de $\mathrm{d}$. Sebastiâo previa que os oficiais inquisitoriais fossem "escusos de pagar fintas, talhas, pedidos, empréstimos, nem em outros alguns encargos que pelos concelhos e lugares aonde forem moradores, forem lançados por qualquer modo ou maneira que seja" ${ }^{67}$ Não pagar a finta, um imposto, por certo extraordinário, cobrado "a partir dos rendimentos da fazenda de cada súdito", segundo Bluteau, era uma boa razão para se almejar um título inquisitorial, ainda mais no período da guerra de Restauração, que foi quando Antonio Gonçalves Prego obteve o seu cargo, e quando se lidava com somas importantes de dinheiro e bens. Sem dúvida uma enorme sinecura para quem exercia atividades financeiras além de ser terratenente. Como poderemos compreender facilmente depois de ter visto suas atividades de prestamista e de administrador de rendas, este pode ter sido, para Antonio Gonçalves Prego, um dos principais atrativos do cargo de despenseiro do tribunal da Inquisição de Lisboa. Não há pesquisas sobre o quanto esses privilégios fiscais da Inquisição eram realmente vantajosos para quem os gozava, e uma investigação mais detida deverá ser feita para comprovar o fato, mas em 1641, por exemplo, estabeleceu-se a décima militar para o financiamento da guerra, imposto direto que incidia inclusive sobre o juro dos empréstimos e que foi cobrado até o fim da guerra, sendo reativado entre 1704 e 1715 e uma segunda vez em $1762 .{ }^{68}$ Os privilégios mencionam apenas os encargos "lançados pelos concelhos e lugares aonde forem moradores”, mas se assimilarmos essa décima à finta, é bem possível que Gonçalves Prego tenha ficado isento do imposto.

Podemos assim ver que o ofício de despenseiro do Santo Ofício, no qual poderíamos imaginar alguém com bons conhecimentos de cálculo e não muito mais do que isso, vivendo atrás de uma janelinha gradeada a passar os parcos produtos necessários à manutenção dos presos dos cárceres inquisitoriais, foi transformado por Antonio Gonçalves Prego, cuja mu-

\footnotetext{
${ }^{66}$ ANTT, CGSO, livro 473, fl. 265v-266.

${ }^{67}$ Carta régia de d. Sebastião de 14 de dezembro de 1562 . Nem todos os oficiais inquisitoriais tiveram sempre direito de gozar estes (e outros) privilégios, mormente a maioria dos familiares. Ver as referências dadas nas notas 33 e 34 .

${ }^{68}$ SILVA, Álvaro Ferreira da. Finanças públicas. In: LAINS, Pedro; SILVA, Álvaro Ferreira da (Org.). História Económica de Portugal 1700-2000. Lisboa: Imprensa de Ciências Sociais, 2004, v. I, p. 245-246. HESPANHA, António Manuel. A Fazenda. In: MATTOSO, José (Dir.). História de Portugal. Lisboa: Círculo de Leitores, 1993, v. 4 (Doord. A. M. Hespanha), p. 217-218.
} 
lher sem dúvida não fazia o "grande exercício de maçaria e outros requisitos do ofício" sua antecessora na posição de esposa de despenseiro, numa sólida base para sua casa. Uma ascensão social no Portugal da segunda metade do século XVII era impensável sem um certificado de pureza de sangue. Uma simples familiatura poderia resolver a situação, mas a entrada no quadro dos oficiais inquisitoriais oferecia não só palpáveis privilégios imediatos, mas também uma porta de entrada a contatos com gente graúda. Teria sido este o caminho que o levou a gerenciar as rendas do arcebispado de Lisboa e em seguida do cabido, de que eram membros muitos dos inquisidores e deputados da Inquisiçáo? Em todo caso, parece-nos ter sido possível demonstrar aqui como o ofício de despenseiro - na verdade possivelmente qualquer desses ofícios - se inseria nas estratégias não só de sobrevivência, mas também de enriquecimento e ascensão social de um filho de ourives e neto de lavradores, ajudando ao mesmo tempo a entender a importância social do palácio do Rossio enquanto centro emanador de legitimidade social.

\section{Fontes primárias}

Arquivo da Cúria Patriarcal de Lisboa, Livro 468.

Arquivo dos Viscondes de Vila Nova de Cerveira, cx. 44, n. 4, 5 e 6; cx. 59, n. 53 e 54.

Arquivos Nacionais da Torre do Tombo

- Conselho Geral do Santo Ofício, livros 140 e 473.

- Inquisição de Lisboa, processos 2725 e 17170.

- Inquisição de Lisboa, livros 104, 106, 107, 108, 112,128, 588, 634 e 927.

- Habilitaçôes do Santo Ofício Agostinho, maço 1, doc. 7; Antonio, maço 10, doc. 403; Antonio, maço 22, doc. 643; José, maço 1, doc. 13; Pedro, maço 10, doc. 254; Salvador, maço 1 , doc. 15 .

- Habilitaçóes da Ordem de Cristo Antonio, maço 48 n. 3.

- Registo Geral de Testamentos, livros 103, 106, 107, 155, 156.

- Registos Notariais de Lisboa, cartório 15A [antigo 7A], cx. 86, livro 471.

${ }^{69}$ HSO, Agostinho maço 1, doc. 7, fl. 2. 


\section{Fontes secundárias}

BLUTEAU, Raphael. Vocabulario portuguez e latino (1712-1728). Disponível em: <http:// www.brasiliana.usp.br/pt-br/dicionario/edicao/1>.

GÓIS, Damião de. Descrição da cidade de Lisboa. Lisboa: Frenesi, 2003 ([1554] trad. Raul Machado, 1· ed. 1937).

PORTUGAL, Fernando; MATOS, Alfredo de. Lisboa em 1758. Memórias paroquiais de Lisboa. Lisboa: Publicaçóes Culturais da Cámara de Lisboa, 1974.

Regimento do dispenseiro do Santo Ofício da Inquisição. In: MEA, Elvira. A Inquisição de Coimbra no século XVI. A Instituição, os homens e a sociedade. Porto: Fundação Eng. António de Almeida, 1997, p. 691-692.

Regimento do Santo Ofício de 1613. In: FRANCO, José Eduardo; ASSUNÇÃO, Paulo de. As metamorfoses de um polvo. Religião e política nos Regimentos da Inquisição portuguesa (séc. XVI-XIX). Lisboa: Prefácio, 2004.

Regimento do Santo Ofício de 1640. In: FRANCO, José Eduardo; ASSUNÇĀO, Paulo de. As metamorfoses de um polvo. Religião e política nos Regimentos da Inquisição portuguesa (séc. XVI-XIX). Lisboa: Prefácio, 2004.

Traslado autentico de todos os privilegios concedidos pelos Reys destes Reynos, e Senhorios de Portugal aos Officiaes, e Familiares do Santo Officio da Inquisição. Lisboa: $\mathrm{Na}$ Officina de Miguel Manescal, 1691.

\section{Referências bibliográficas}

AMORIM, Inês. Património e crédito: Misericórdia e Carmelitas de Aveiro (séculos XVII e XVIII). Análise Social, n. XLI, p. 693-729, 2006.

ARAÚJO, Ana Cristina. A morte em Lisboa. Atitudes e representaçôes. 1700-1830. Lisboa: Notícias Editorial, 1997.

BAIÃO, António. A Inquisição em Portugal e no Brasil. Subsídios para a sua história. Lisboa: Arquivo Histórico Português, 1920.

BICALHO, Maria Fernanda. Ascensão e queda dos Lopes de Lavre: secretário do Conselho Ultramarino. In: MONTEIRO, Rodrigo Bentes et al. Raizes do privilégio. Mobilidade social no mundo ibérico do Antigo Regime. Rio de Janeiro: Civilização Brasileira, 2011, p. 283-315. COUTO, Dejanirah. História de Lisboa. Algés: Gótica, 2004 [1. ed. em francês: 2000]. DURÃES, Andréia. Grupos intermédios em Portugal (1600-1850). Uma aproximação ao vocabulário social. Topoi, n. 27, p. 318-343, dez. 2013. 
FIGUEIRÔA-RÊGO, João. Entre honra e suspeita. A desconcertante ambiguidade social dos agentes do tabaco nos séculos XVII e XVIII. In: LÓPEZ-SALAZAR, Ana Isabel; OLIVAL, Fernanda; FIGUEIRÔA-RÊGO, João (Coord.). Honra e sociedade no mundo ibérico e ultramarino. Inquisição e ordens militares. Séculos XVI-XIX. Casal de Cambra: Caleidoscópio, 2013, p. 273-293.

GALLO, Alberto. La venalidad de oficios públicos durante el siglo XVIII. In: BELLINGERI, Marco (Coord). Dinámicas de Antiguo Régimen y orden constitucional. Representación, justicia y administración. Siglos XVIII-XIX. Turim: Otto Editore, 2000, p. 97-177.

GANDELMAN, Luciana. O poder dos bens deste mundo: um exercício de indagaçáo sobre o testamento seiscentista de João de Matos de Aguiar. In: SÁ, Isabel dos Guimarães; GARCÍA FERNÁNDEZ, Máximo (Org.). Portas adentro: comer, vestir, habitar (ss. XVIXIX). Coimbra/Valadollid: Imprensa da Universidade/Secretariado de Publicaciones, 2010, p. 273-293. Disponível em: <https://digitalis.uc.pt/pt-pt/livro/o_poder_dos_bens_deste_ mundo_um_exerc\%C3\%ADcio_de_indaga\%C3\%A7\%C3\%A3o_sobre_o_testamento_ seiscentista_de_jo\%C3\%A3o>.

HESPANHA, António Manuel. A fazenda. In: MATTOSO, José (Dir.). História de Portugal. Lisboa: Círculo de Leitores, 1993, v. 4 (Coord. A. M. Hespanha), p. 217-218.

LOPES, Bruno. Família e Transmissão de cargos no Santo Ofício: o meirinho da Inquisição de Évora. In: SANTOS, Zulmira C. (Coord.). Família, espaço e património. Porto: CITCEM, 2011, p. 283-299. Disponível em: <http://ler.letras.up.pt/uploads/ficheiros/10700.pdf>.

MARTINS, João Furtado. Corrup̧ãao e incúria no Santo Ofício. Ministros e oficiais sob suspeita e julgamento. Lisboa: Universidade Católica Portuguesa, 2015.

MEA, Elvira. A Inquisição de Coimbra no século XVI. A Instituição, os homens e a sociedade. Porto: Fundação Eng. António de Almeida, 1997.

MENDONÇA, José Lourenço D. de; MOREIRA, António Joaquim. História dos principais actos e procedimentos da Inquisiçẫo em Portugal. Lisboa: Círculo de Leitores, s.d. [1979].

OLIVAL, Fernanda. Os lugares e espaços do privado nos grupos populares e intermédios. In: MATTOSO, José. História da vida privada em Portugal. A Idade Moderna (Coord. De N. G. Monteiro). Lisboa: Círculo de Leitores/Temas e Debates, 2010, p. 244-263.

OLIVAL, Fernanda. Economía de la merced y venalidad en Portugal (siglos XVII e XVIII). In: ANDÚJAR Castillo, Francisco; FELICES de la Fuente, María del Mar (Ed.). El poder del dinero: ventas de cargos y honores en el Antiguo Régimen. Madri: Biblioteca Nueva, 2011, p. 345-357.

PINTO, Maria do Carmo Teixeira. Um palácio no Rossio: ciclos de vida (séculos XV a XIX). In: ACTA DAS SESSÓES. I COLÓQUIO TEMÁTICO: O MUNICÍPIO DE LISBOA E A DINÂMICA URBANA (SÉCULOS XVI-XX). Lisboa: Câmara Municipal de Lisboa, 1995, p. 163-175. 
PROSPERI, Adriano (Dir.). Dizionario Storico dell'nquisizione. Pisa: Edizioni della Normale, 2010, $4 \mathrm{v}$.

ROCHA, Maria Manuela. Crédito privado em perspectiva comparada (séculos XVII-XIX). Gabinete de História Económica e Social: Lisboa, 1998. Disponível em: <http://www. repository.utl.pt/bitstream/10400.5/908/1/WP10.pdf>.

SILVA, Álvaro Ferreira da. Finanças públicas. In: LAINS, Pedro; SILVA, Álvaro Ferreira da (Org.). História Económica de Portugal 1700-2000. Lisboa: Imprensa de Ciências Sociais, 2004, v. I, p. 237-261.

STUMPF, Roberta. Venalidad de oficios en la monarquía portuguesa: un balance preliminar. In: ANDÚJAR Castillo, Francisco; FELICES de la Fuente, María del Mar (Ed.). El poder del dinero o: ventas de cargos y honores en el Antiguo Régimen. Madri: Biblioteca Nueva, 2011, p. 331-344.

WADSWORTH, James. Os familiares do número e o problema dos privilégios. In: VAINFAS, Ronaldo; LAGE, Lana; FEITLER, Bruno (Org.). A Inquisição em xeque: temas, controvérsias, estudos de caso. Rio de Janeiro: EdUERJ, 2006, p. 97-111. 